\title{
Construction of Public Health Safety Legal System Framework from the Perspective of Precautionary Principle
}

\author{
Zhuqi He \\ Juris Master, Chongqing University (Chongqing, China) \\ E-mail: 948622751@qq.com \\ https://orcid.org/0000-0001-6965-8220
}

He, Zhuqi (2020) Construction of Public Health Safety Legal System Framework from the Perspective of Precautionary Principle. Ukrainian Policymaker, Volume 6, 32-42. https:// doi.org/10.29202/up/6/4

The outbreak of COVID-19 has plunged China and the world into a dilemma in dealing with sudden social and public health incidents. The epidemic has affected both the economy and society as a whole. From the perspective of the principle of precautionary, the existing legal framework for public health security has three major dilemmas, namely, lack of information regulation, unbalanced decentralization regulation, and lack of effectiveness regulation. In order to better cope with the epidemic situation caused by the novel coronavirus, the legal system of the public health system should be reconstructed from the three dimensions of perfect information regulation, decentralization regulation and effectiveness regulation to deal with the crisis.

Keywords: coronavirus, precautionary principles, public health safety, legal system framework

Received: February 28, 2020; accepted: March 26, 2020

\section{Introduction}

At the end of December 2019, an unknown virus began to appear. After the coronavirus was recognized and worried by the public, the new virus epidemic has already started to sweep across China. According to the official data released by the National Health Commission, the cumulative number of confirmed cases in Wuhan City, Hubei Province is 67,803, with a cumulative total of 3,219 deaths, and the number of diagnosed cases in 31 provinces and Xinjiang Production and Construction Corps are 82,052, with a total of 3,339 deaths. However, this data is still increasing and fluctuating. Confronting unknown viruses and diseases, mankind seems to be in a dilemma: where did viruses come from? How did it spread? How should we face the challenge and solve unknown problems? With the current level of human knowledge

(C) He, Zhuqi, 2020 
and technology, it is impossible to predict the scope of the problem (Tan, 2020). "Every time the threat becomes more urgent and obvious, we find ourselves unable to use scientific, legal, and political measures to determine evidence, find the cause, and remedy it" (Zhao, 2009). The "Precautionary Principle" comes from the book "Risk Society Towards a New Modernity," published by the German scholar Ulrich Baker. It first proposed the risk society theory, and the principle of precautionary was reconstructed under this theory.

To deal with the unknown viruses and diseases, we should change our strategy from the past dangerous response to risk prevention and take precautions. The fear and confusion of the unknown virus is pushing us forward in accordance with the "precautionary principle." Social development has shifted towards a risk society, and the principle of prevention using law as a measure should also be adapted to the needs of the formulation of the precautionary principle. The Chinese "Public Health Emergency Response Regulations," "Infectious Diseases Prevention and Control Law," "Emergency Response Law," "Border Health and Quarantine Law," "Animal Epidemic Prevention Law," and other legal norms have not yet been fully adapted to the requirements of the precautionary principle. Therefore, this article mainly takes the most representative "Public Health Emergency Response Regulations," "Emergency Response Law," and "Infectious Disease Prevention and Control Law" as examples to discuss the response to imperfect public health laws issues, and then discuss the construction of the legal system framework.

\section{Analysis of the existing legal framework for public health safety}

The legal framework is divided into form and substance. The formal legal framework is the composition form of a law, and the substantial legal framework has different frame models according to different classifications. This article analyzes the framework according to the implementation form of the law and the implementation subject, and classifies the legal framework into an information adjustment framework, a decentralized adjustment framework, and an effectiveness adjustment framework. The so-called information regulation framework is to analyze how the information network of the relevant government department operates in the legal process when responding to prominent social public health events; the so-called decentralized regulation framework refers to the regulation stipulate the division of the powers of law enforcement actions by different actors responding to public social emergencies. The so-called effectiveness adjustment framework refers to the aspects in which the effectiveness of the existing social public health emergencies is mainly reflected and what are the lacks of legal norms that fail to achieve effective purposes. When a health emergency occurs, the role of the information network as a central hub is to drive different government between the upper and lower levels, and between the same levels to take immediate response to the outbreak. And when the information network has covered the law enforcement agencies at the upper and lower levels and at the same level, it has promoted its decentralization. The final validity adjustment is the expected legal effect that can be achieved after the completion of the preliminary actions prescribed by the law.

\section{(1) Analysis of information adjustment framework}

The information regulation framework pointed out that in this article refers to the hierarchical reporting system of sudden social and public health events procedurally. As a public authority department, the government plays a leading role in emergency events, with 
which reporting on the epidemic is particularly important. Crises in public health emergencies will pose a serious threat to the basic values of social systems and the framework of the code of conduct. Urgency and high uncertainty call into question the ability of the government to respond to force majeure circumstances (Zhu \& Peng, 2020). "The Emergency Response Law" divides emergency events into natural disasters, accident disasters, and public health events according to the degree of social harm, impact range, and other factors. As well as emergency situations, are divided into four major levels: particularly significant, major, large and general. The coronavirus is a public health event, and it should be classified as a particularly significant public health event according to its damage. According to the Chinese "Regulations on Emergency Response to Sudden Social and Public Health Incidents," under ideal circumstances when a suspicious infectious disease occurs in an area, the State Council needs to be informed and altered within 9 hours. If the new crown epidemic is passed on from person to person within 9 hours, if no emergency response measures are taken, hundreds of people will be affected. To this end, China has formulated the "Technical Specification for Direct Reporting of the National Health Statistics Network," which is a VPN private network established using national public data network resources. In addition, the general public cannot access the intranet of the supplement health information data (Zhou \& He, 2009). As far as the occurrence of the coronavirus epidemic is concerned, the doctor who first discovered the unknown virus from Wuhan Central Hospital, was not clear whether he has the rights and responsibility doctor belongs to report to the higher authorities directly. Therefore, when the relevant doctor found the suspicious virus, it did not immediately draw attention, nor take immediate response to emergency measures. As a result, it may be one of the reasons for missing the best opportunity as well to control the spread of the virus.

\section{(2) Analysis of the decentralization adjustment framework}

The decentralization adjustment framework referred to two aspects. One is the relationship between the central government and the local government; the other one is the relationship between the local government and the health administrative department at the same level. The basic organizational form of a modern country is a bureaucratic organizational form, the core of which is that the central government has the power of administrative planning, especially in the power of personnel arrangements and resource allocation (Zhou, 2011). In response to sudden social public health incidents, the central government is in a dominant position in emergency response and emergency plan setting. The specific manifestations of this bureaucracy include, the emergency response work of emergencies implements the principles of unified leadership and hierarchical responsibility; the State Council establishes a national emergency response command headquarters; the State Council administrative department of health in accordance with the requirements of classification guidance and rapid response, formulate National emergency plans for emergencies, and submitted to the State Council for approval; the state establishes a unified emergency prevention and control system and other aspects. This form of responding to emergencies in social health is "bar-shaped," and the form itself shows that the central department is not only simply a decentralized person, but also a supervisor and a direct participant (Yu, 2016). In the legal provisions, due to the unclear division of responsibilities between the central and local governments, only at a certain level, the governments of provinces, autonomous regions, and municipalities directly under the central government are authorized by the central government in accordance with the national emergency response plan, combined with actual local conditions Formulate emergency plans 
for emergencies in this administrative area. The relationship between the local government and the health administrative department at the same level is mainly to divide the responsibilities in response to the "tragedy of the public land" and the "prisoner's dilemma," which reflects that the individual's rational strategy might lead to the collective irrational ending (Ostrom, 2000; Bazaluk et al., 2020). As the main body in response to the sudden public health incidents in the law of the local governments at various levels and the health administrative departments at all levels, their division of responsibilities is particularly important during the response to the epidemic.

\section{The division of responsibilities is shown below:}

\begin{tabular}{|l|l|}
\hline Enforcement subject & Responsibilities \\
\hline $\begin{array}{l}\text { Government departments at } \\
\text { all levels }\end{array}$ & $\begin{array}{l}\text { Responsible for publicity and education; implementing emer- } \\
\text { gency contingency plan requirements; responsible for technical } \\
\text { investigation, confirmation, handling, control, and evaluation of } \\
\text { emergencies }\end{array}$ \\
\hline $\begin{array}{l}\text { Health administrative } \\
\text { department }\end{array}$ & $\begin{array}{l}\text { Publicize and educate the personnel of medical institutions; be } \\
\text { responsible for formulating emergency reporting standards for } \\
\text { emergency; release emergency information to the society }\end{array}$ \\
\hline Joint responsibility & $\begin{array}{l}\text { Appropriate subsidies and health allowances should be given to } \\
\text { medical and health personnel participating in emergency treat- } \\
\text { ment; emergency personnel should be commended and reward- } \\
\text { ed for contributing to emergency treatment; sickness, disability, } \\
\text { and death caused by participating in emergency treatment In } \\
\text { accordance with the relevant regulations of the state, the em- } \\
\text { ployees are given corresponding subsidies and pensions. }\end{array}$ \\
\hline
\end{tabular}

It can be confirmed from the above figure that government departments at all levels are mainly responsible for the implementation of emergencies and implement the actual level of the emergency plan requirements. The administrative department of health is responsible for formulating technical specifications, which follows its original purpose. However, under the actual operation of the epidemic situation, the main body and procedures for publicizing the epidemic situation, as stipulated by laws and regulations, are inconsistent in actual implementation. Since the occurrence of the epidemic is divided into different levels, it is difficult to implement the procedures for the announcement of epidemic information and the implementation of the procedures for the announcement of the epidemic at different levels and types. However, the announcement of the epidemic situation is an important measure that traps the hearts of the people of the country. For the people in the non-epidemic area as well as the people in the epidemic area, the development trend of the epidemic situation and on-time news is crucial.

\section{(3) Analysis of effectiveness adjustment framework}

The validity adjustment framework referred to the legal effects that can be produced by the existing legal framework system, including effective legal effects and invalid legal effects. 
Among these, the invalid legal effect is mainly due to the lack of validity of the legal framework. Consequently, the analysis of the effectiveness adjustment framework is to break through the legal effects of the formal aspect and face the legal effects of the substantive aspect. On the other hand, the effectiveness adjustment framework is to distinguish the actuality level of the legal system, and the formality should be changed to actuality, so that the lack of actuality will become one of the reasons why the risk cannot be estimated before the outbreak.

China has experienced and learned the lesson from the "SARS" epidemic and formulated relevant laws and regulations to prevent prominent social and public health incidents. These laws and regulations have played an extremely important role in combating the epidemic. Its effectiveness mainly reflects the compensation for the past epidemic reporting system, the emergency response system to respond to the epidemic, and the epidemic situation announcement system. The perfection of institutional norms has greatly contributed to limiting the spread of the coronavirus, which also made China the first country in the world to effectively control the exacerbation of the epidemic. In the aspect of effective regulation, there are inevitably opposite examples. For example, the specific manifestations include the failure to formulate a perfect emergency plan in the legal norms, and the failure to establish a unified emergency disposal command system in accordance with relevant laws. Various normative documents have irregularities, uncoordinated measures, and even violations of laws. They mainly address the problem of inadequate filing and review of regulatory documents for epidemic prevention (Xia, 2020). In addition, the legal provisions for responding to social health emergencies do not confer appropriate law enforcement power that can adapt to the specific conditions of each region. In this respect, the epidemic situation cannot be resolved by local measures.

\section{Three dilemmas under the principle of precautionary}

Through the analysis of the legal framework, it is found that the relevant laws and regulations used to deal with sudden social public health incidents have flaws. Imperfect laws and regulations will bring corresponding problems, that is, the actual implementation of emergency operations and risk prevention. The outbreak of the COVID-19 epidemic is a national crisis and an era crisis affecting society, politics, and the economy. Under panic, the local government and the central government are the core to deal with the crisis and the center for coordinating social stability. When facing the crisis, the local government should realize that the crisis may become a regional or even a global crisis. Therefore, when facing a crisis, local governments, and health administrative departments at the same level should increase awareness and be alert of the importance of risk prevention. However, the regulation and behavior of the government and administration of health administrative departments mainly stem from the regulation of laws and regulations. Due to the blank of information regulation, the imbalance of decentralization regulation, and the lack of effectiveness regulation in China's current laws and regulations, when facing the new outbreak of the epidemic, we still went through many detours in the face of crisis.

\section{(1) Lack of information regulation, lack of preventative measures in emergency}

To understand the principles of precautionary, we must first distinguish between the definitions of "risk" and "danger." The focus of modern administrative law on public health incidents is to prevent hazards, and the terms "hazard" and "risk" are in the meaning and 
governance Modes belongs to different categories. "Danger is a situation in which, during the foreseeable time, with a high degree of probability that damage will occur in the course of uninterrupted facts; if empirical rules have not yet determined the possibility of damage, it cannot be scientifically excluded, and the possibility of its occurrence belongs to the category of risks. The resulting problem is how to deal with uncertain risks, the law with the protection of legal interests as the core" (Zhang, 2020). Therefore, when dealing with dangers and risks, the measures and intensity it takes are quite different. On the other hand, the prevention, management, and decision-making of risks all belongs to the administrative category of order. Because of the abstract nature of risks, they are not the actual damage that occurs in detail; as a result, they cannot be specified in the law, while this gives administrative agencies the discretion to adopt policies to deal with risks. The Emergency Regulations for Public Health Emergencies are formed to effectively prevent timely control and eliminate the hazards of public health emergencies, to ensure public health, safety, and maintain normal social order. The basis of its formulation contains the meaning of hazard prevention. However, prevention of hazards is different from risk prevention and might have different effects at the practical level. For example, in the initial stage of the outbreak, the acceptance of outbreak information was within the discretion of the relevant departments. When "Unknown Pneumonia" was proposed by some groups, the relevant departments were hindered at the initial stage of transmitting information because they did not consider risk prevention. From the framework analysis, it can be seen that the time taken for the information source of infectious diseases to be reported to the State Council and transmitted to its neighboring provinces, autonomous regions, and municipalities is are already highly valued. Nevertheless, if it is hindered in the initial stage of information transmission, it might lose the best opportunity in control of the epidemic situation. The outbreak of the coronavirus epidemic happened right. During the Spring Festival period with the largest number of mobile populations in China, and it began on the eve of the Spring Festival. It can be seen from which the importance of risk prevention to information regulation. On account of the core of laws and regulations has not been transferred to the core of risk prevention, and the disorder of information regulation cannot play its stabilizing role. The root cause of the maladjustment of information lies in national activities, which may become an origin of risk. If the government's discretion on public safety emergencies is not regulated and controlled, it will become an unpredictable risk diffuser and a source of specific damage. The reason is that the government's remarks will affect the public's response to public health incidents and the extent to which medical institutions and media attach importance to the incident. To deal with "risk," we must adopt different system construction from "dangerous" response, so as to form perfect response measures in different situations.

\section{(2) Decentralization adjustment imbalance, lack of coordination in emergency}

The disease is still spreading, and the emergency measures are not only in the epidemic area but also in the non-epidemic area. The cross-regional characteristics of emergency measures mean that the coordination and cooperation between them is extremely necessary, and the imbalance of decentralized regulation might lead to a lack of coordination in emergencies, and corresponding problems may occur during the implementation of emergency measures. In the course of this epidemic, the imbalance of decentralization is mainly reflected in:

1. The imbalance between central and local decentralization, which in decentralization between the central and local governments, is mainly reflected in the emergency 
reporting system. Local governments or grass-roots health authorities can only report through layers when they discover "unknown pneumonia." The central government will eventually formulate an emergency plan system. The local government can only carry out the implementation according to the plan formulated by the central government. Whether it is the new coronary pneumonia or the SARS virus this time, its ability to spread and speed are extremely high and fast. At this time, the local government needs to immediate response to the unknown virus in time to prevent the risk of transmission. For a modern government that undertakes public management duties, the emergence of a crisis is a warning signal. If an organization can grasp the opportunity of a crisis and respond quickly to the causes of the crisis and the crisis management process, the crisis can be a rational and dynamic government. In other words, it can become an external driving force for public policy improvement (Xue \& Zhang, 2003).

2. The division of power between the local government and health authorities is unbalanced. The imbalance of decentralization adjustment is reflected as well as in the imbalance of power division between local governments and health authorities, and it is mainly due to the unclear provisions of laws and regulations. In the analysis of the legal framework, it was found that, theoretically speaking, local governments and health authorities have their own duties when responding to the epidemic and have their own exclusive jurisdictions. Yet still, in the actual operation process, it may encounter more problems than the law requires, and its jurisdiction and power division needs to be further refined. For instance, in response to an outbreak, there is no unified emergency response command institution. Local governments and health authorities have their own duties and are lack of cooperation with each other. As another example, in the face of epidemic reporting, the law only stipulates that the health administrative department is responsible for formulating reporting standards, and government departments are responsible for the control and evaluation of the epidemic. It is not clear which department should report the level of the epidemic at different levels and who should report between the government department and the health administrative department between different levels. At the beginning of the coronavirus, data release was faced with problems. Notably, the untimely release of data in the epidemic area would lead the public to lose their trust in the government and to cause panic.

\section{(3) Lack of effectiveness adjustment and lack of overall risk prevention}

Efficiency is the ultimate goal of legal norms to deal with sudden outbreaks. Achieving the effectiveness of epidemic control and public stability is the ultimate destination of legal norms. The relevant laws and regulations formulated by our country in response to the SARS virus in response to emergencies in social public health events and infectious diseases have played an important role in response to the COVID-19. Even so, those laws still pale in front of the outbreak.-The lack of effectiveness is mainly manifested in the lack of a holistic approach to risk prevention by government departments at all levels.

Cities in closed provinces do not have enough medical equipment, basic necessities, and the necessary safety conditions for residents. Governments at all levels have successively imitated Wuhan's relevant measures to respond to the epidemic. However, in the epidemic provinces, the economic conditions, medical conditions, and population structure differ from 
different regions. When the nation's attention is focused on Wuhan, other cities in Wuhan, such as Jingzhou and Yichang were facing a greater crisis since there is no response mode that suits the actual situation of the city. Compared with its surrounding cities, Wuhan has advanced medical conditions and more convenient transportation conditions. Still, its surrounding cities do not own, and the local government's financial allocation also has corresponding problems. The widening of this difference has led various local governments to act independently in response to the epidemic situation in various places, and the response measures taken by some local governments are completely incompatible with the law. Article 17 of the "Administrative Compulsory Law" states: "Administrative coercive measures shall be implemented by the administrative organs prescribed by laws and regulations within the scope of statutory powers." Administrative coercive measures shall be implemented by qualified administrative law enforcement personnel of the administrative organs, and no other person may be entrusted to implement them. In practice, it is debatable whether the rural villagers and community security personnel in some places have implemented the lawful means of enforcement spontaneously or in accordance with the instructions. Administrative law enforcement personnel in some localities do not consider the degree of the subjective malignancy of the perpetrators and the degree of social harm caused by illegal acts. Excessive law enforcement has impaired the fairness and justice of laws and regulations.

\section{Construction of a legal system framework for public health emergencies based on the principle of risk prevention}

The principle of risk prevention was first proposed in the 1982 United Nations World Charter for Nature, but its application is no longer limited to the field of environmental law. In the process of changing from order administration to payment administration, the government, as an assistant and servicer to the people's happy life, should provide residents with a more comprehensive life guarantee while preventing risks. The principle of risk prevention requires decision-makers to take action when the corresponding evidence, information is insufficient or difficult to explain. It is granted to administrative agencies to judge whether there is a risk that needs to be prevented according to their own professional knowledge (Zhao, 2009). The emergence of law enforcement disorder in the case of disease outbreak is mainly due to the difficulty of government organizations to identify and manage emergency public health events and emergencies, as well as the lack of infrastructure construction. As a result, the outbreak of disease requires adjustment of the legal system, and the establishment of a legal system for public health emergencies based on the principle of precautionary.

\section{(1) Improving the information regulation framework and realize risk prevention}

The information regulation framework is the central hub for spreading information in response to outbreaks when the disease occurs. This central hub affects the administrative actions of the government and various health administrative departments. It can also affect the guidance of the people by the news media and public opinion. At the stage of the outbreak, the most fundamental thing is to rely on the transmission of information to arouse the vigilance of the relevant government and the person in charge to take precautionary measures.

First of all, improving the information regulation framework first requires shortening the time for information transfer. In response to the occurrence of an emergency epidemic, it should be able to report from the grass-roots to the central government within a short period of time, 
and the direct reporting system currently adopted in China is to report at the internal network level. This is not conducive to the prevention of sudden outbreaks, and the transmission speed of online public opinion should be faster and more accurate. When the "unknown pneumonia" claims spread on the Internet, the official has not yet determined the authenticity of the news, and the best way to shorten the reporting time is for the grass-roots government or health administrative department to confirm its source and report it across levels. Due to the administrative operation system of "bureaucracy," the central government must issue general orders, and the central government will obtain information on the epidemic situation to other provinces, autonomous regions, and municipalities in the shortest time.

The efficiency of the municipalities directly communicating information with each other is more rapid.

Secondly, improving the information regulation framework requires laws and regulations to strictly distinguish between "risk" and "danger." For example, a well-known disease or natural disaster should be defined as a "danger category." The most fundamental purpose of dealing with the danger category is to eliminate the danger. The response to "risk" is in the unpredictable range and intensity of communication of the relevant government departments. The outbreak of the coronavirus cannot be predicted before its outbreak, but when it has characteristics similar to SARS, it is necessary to take preventive measures when it is distinguished from ordinary pneumonia by professionals. It is impossible to ask experts to determine the source of a disease or even formulate a treatment plan in a short period of time, but we should be able to determine whether it has potential dangers. Under a risk society, government departments, as the implementers of administrative tasks, should even consider the existence of risks. Therefore, the definition of risks in laws and regulations should be adjusted in a timely manner to enhance its preventive function.

\section{(2) Improve the decentralization adjustment framework and enhance coordination}

Emergent public health incidents generally belong to the category of public affairs, and the management belongs to the state. Private individuals do not have the corresponding enforcement power. Consequently, citizens give the state the power to exercise. The state should be a trustee with respect to the environment, that is, manage, protect, and use trustees in good faith (Keith, 2000). However, as a whole, the state is still an abstract concept in the actual implementation process implemented by various departments and administrative agencies. In response to the epidemic situation, the main body of the emergency plan includes the vertical central and local governments, as well as the horizontal local governments and health administrative departments. Therefore, the division of its power and function is the best way to avoid the "tragedy of public land" and "prisoner's dilemma."

First of all, the division of emergency law enforcement between the central and local governments should be resolved. In the current public health emergency laws and regulations formulated by our country, the separation of duties and responsibilities is small between the central and local governments, but more focused in local initiatives after the central government has given instructions. However, in actual operation, due to the serious epidemic situation, commonly, there will be joint enforcement by the central and local governments. When the joint enforcement by the central and local governments occurs, the local government will lose its right to speak. However, local governments at all levels have a higher level of understanding than local areas, so the division of responsibilities between the central and local governments should be clearly defined in the emergency legal system. 
Secondly, the division of responsibilities between the local government and the health administrative department at the same level should be distinguished clearly to avoid overlapping powers and law enforcement vacuums. Although the division of responsibilities between the health administrative department and the local government is clear in the law, in the actual law enforcement process, the lack of refinement somehow leads to chaotic law enforcement. Therefore, the construction of new laws and regulations to deal with sudden unexpected social and public health incidents should focus on a deeper level of subdivision and make provisions for liability. Only when the functions and the consequences of responsibilities can be specified clearly, can the administrative enforcement of various departments be more efficient.

\section{(3) Improve the effectiveness adjustment and enhance the overall}

The most fundamental measure to improve the effectiveness of adjustment is to adopt measures to local conditions in responding to sudden outbreaks. Different law enforcement methods should be adopted in the face of outbreaks in different regions. Special financial allocations should be made for regions with relatively weak finances to fund medical activities of medical institutions and the people's normal living security. Greater attention should be paid to areas with weak medical facilities, and more medical personnel should be dispatched to enhance the supply of medical equipment to ensure the health of medical personnel. As far as the fiscal part is concerned, local finance can be appropriately relaxed to allow it to use taxation legally and reasonably for local relief. However, adapting to local conditions does not mean that we are independent, since everyone is connected, and global awareness should be gradually being heightened. Government departments must recognize the spread and crossregional risks.

\section{Conclusions}

On the issue of how the law responds to sudden social and public health incidents, three response mechanisms are proposed within the existing legal framework system, that is, to improve the information regulation framework, the decentralization regulation framework, and the effectiveness regulation framework. Since 2003, China has paid attention to sudden social public health incidents and formulated a series of laws and regulations to respond to emergency moments. However, in this epidemic, the old laws and regulations are no longer adapt to the large-scale outbreak of infectious diseases. The imperfect information reporting mechanism has hindered the risk prevention of the COVID-19 situation, so that the risk expansion has quickly become a threat. The chaos brought by the epidemic also provided opportunities for illegal administration, and excessive law enforcement infringed upon the rights of citizens, which led to reconsidering the old decentralized regulation system. Finally, under the great success of China's fight against the Coronavirus, it is also necessary to reflect and decisively summarize the detours in fighting the epidemic. Effectiveness also requires Pareto optimality in law enforcement.

The future is full of uncertainties and risks. With the deterioration of the global environment, new viruses and unpredictable natural disasters will not become extinct because of our victory in one fight. As a consequence, the construction of emergency laws and regulations should incorporate the principle of risk prevention. Of course, risk prevention does not mean excessive law enforcement. Only by accurately grasping the boundaries of risk prevention can we actively respond to crises. 


\section{References}

Bazaluk, Oleg, Denys Svyrydenko, Larysa Kharchenko, and Oleksandra Kachmar (2020) Communication-Dialogic concept of Education in the context of modern philosophical discussions. Revista Dilemas Contemporáneos: Educación, Política y Valores. Year VII, Publication no.2, January 2020.

Keith, Alexander (2000) International Environmental Law. Translated by RuoSi Zhang. Beijing: Law Press.

Ostrom, Eleanor (2000) Governance of Public Affairs. Shanghai Sanlian Bookstore Press.

Tan, Yusheng (2020) Toward a law of healthy peoples: From the Perspective of the Right to Health. Future Human Image, Volume 13, 113-125. https://doi.org/10.29202/fhi/13/12

Xia, Zhenglin. Legal issues involved in fighting the epidemic situation and countermeasures. Democracy and Legal Times, 2020-03-07 (002).

Yu, Yang (2016) Joint Law Enforcement: A Response Mechanism to Govern Paradox Taking Joint Law Enforcement of Marine Environmental Protection as an Example. Journal of Public Administration, 13 (02).

Zhang, Bao (2020) From Hazard Prevention to Risk Prevention: Risk Turning of Environmental Governance and System Adjustment. Law Forum, 35 (01): 22-30.

Zhao, Peng (2009) Risk, Uncertainty and Risk Prevention Principles — An Investigation from the Perspective of Administrative Law. Administrative Law Collection, 000 (001), 187 211.

Zhou, Sujuan, and $\mathrm{Na} \mathrm{He}$ (2009) Establishment of a reporting platform for public health emergencies. Compilation of the First National Public Health Academic Conference of the Chinese Medical Association and the Fourth Chinese Field Epidemiology Training Project.

Zhou, Xueguang (2011). Authoritative System and Effective Governance: The Institutional Logic of Contemporary Chinese National Governance. Open Times (10): 69-87.

Zhu, Zhe, and Zongchao Peng (2020) Government role determination in public health emergencies: challenges and countermeasures. Southeast Academic, 2020 (02): 11-17.

Xue, Lan, and Qiang Zhang (2003) SARS and the Construction of China's Crisis Management System SARS and the construction of China's Crisis Management System. Journal of Tsinghua University: Philosophy and Social Sciences Edition, 2003 (04): 4-9. 